\title{
Ultraviolet B radiation modifies circadian time in epidermal skin and in subcutaneous adipose tissue
}

\section{Nikkola, Veera}

2019-05

Nikkola , V , Miettinen , M E , Karisola , P , Grönroos , M , Ylianttila , L , Alenius , H , Snellman , E \& Partonen , T 2019 , ' Ultraviolet B radiation modifies circadian time in epidermal skin and in subcutaneous adipose tissue ', Photodermatology, Photoimmunology \& Photomedicine , vol. 35 , no. 3 , pp. 157-163 . https://doi.org/10.1111/phpp.12440

http://hdl.handle.net/10138/307275

https://doi.org/10.1111/phpp.12440

acceptedVersion

Downloaded from Helda, University of Helsinki institutional repository.

This is an electronic reprint of the original article.

This reprint may differ from the original in pagination and typographic detail.

Please cite the original version. 
DR VEERA NIKKOLA (Orcid ID : 0000-0002-0450-2871)

PROFESSOR TIMO PARTONEN (Orcid ID : 0000-0003-1951-2455)

Article type : Original Article

\section{ULTRAVIOLET B RADIATION MODIFIES CIRCADIAN TIME IN EPIDERMAL SKIN AND IN SUBCUTANEOUS ADIPOSE TISSUE}

Nikkola Veera ${ }^{1,2,3^{*}}$, Miettinen Maija $E^{4}$, Karisola Piia ${ }^{5}$, Grönroos Mari $^{3}$, Ylianttila Lasse ${ }^{6}$, Alenius Harri ${ }^{5,7}$, Snellman Erna ${ }^{1,2}$, Partonen Timo ${ }^{4}$

\section{Affiliations:}

${ }^{1}$ Faculty of Medicine and Life Sciences, Department of Dermatology and Venereology, University of Tampere, Tampere, Finland;

${ }^{2}$ Department of Dermatology and Allergology, Tampere University Hospital, Tampere,

Finland;

${ }^{3}$ Department of Dermatology and Allergology, Päijät-Häme Social and Health Care Group, Lahti, Finland;

${ }^{4}$ Department of Public Health Solutions, National Institute for Health and Welfare, Helsinki, Finland;

${ }^{5}$ Department of Bacteriology and Immunology, Faculty of Medicine, Medicum, University of Helsinki, Helsinki, Finland;

This article has been accepted for publication and undergone full peer review but has not been through the copyediting, typesetting, pagination and proofreading process, which may lead to differences between this version and the Version of Record. Please cite this article as doi: 10.1111/phpp.12440

This article is protected by copyright. All rights reserved. 
${ }^{6}$ STUK - Radiation and Nuclear Safety Authority, Helsinki, Finland;

${ }^{7}$ Institute of Environmental Medicine, Karolinska Institutet, Stockholm, Sweden.

Short title: UVB modifies circadian time in human skin

The research was conducted in Päijät-Häme Social and Health Care Group, Department of Dermatology and Allergology, Lahti, Finland.

*Corresponding author at: The Faculty of Medicine and Life Sciences, Department of Dermatology, 33014, University of Tampere. FI-33014 Tampere, Finland, +358 3355 111, kangaspunta.veera.k@student.uta.fi.

\section{Background}

Recent findings suggest that circadian time regulates cellular functions in the skin and may affect protection against ultraviolet radiation (UVR). It is not known, however, whether UVR through skin directly affects the expression of circadian genes. We investigated the effect of ultraviolet-B (UVB) exposure on cryptochrome circadian clock 1 (CRY1), cryptochrome circadian clock 2 (CRY2), and circadian associated repressor of transcription $(C I A R T)$ genes.

This article is protected by copyright. All rights reserved. 


\section{Methods}

Healthy volunteers $(n=12)$ were exposed to narrow-band UVB radiation of 4 standard erythemal dose (SED). Epidermal/dermal and subcutaneous adipose tissue samples were obtained by punch biopsies from irradiated and non irradiated skin $10 \mathrm{~cm}$ away from the irradiated site 24 hours after UVB exposure. Gene expression of $C R Y 1, C R Y 2$, and CIART was measured using RT-PCR (TaqMan).

\section{Results}

UVB radiation affected mRNA expression in the epidermal/dermal skin and in the subcutaneous adipose tissue. It down-regulated expression of CRY2 gene in the epidermal/dermal skin, whereas it up-regulated expression of $C R Y 1$ and CIART genes in the subcutaneous adipose tissue.

\section{Conclusion}

We showed for the first time that UVB radiation affects expression of circadian genes in the subcutaneous adipose tissue. Further studies are warranted to understand the mechanisms in detail.

Keywords: CRY1, CRY2, CIART, mRNA, gene

This article is protected by copyright. All rights reserved. 


\section{INTRODUCTION}

Ultraviolet radiation (UVR) reaching the skin is a carcinogen, inducing immunosuppression and DNA mutations (1) and the wavelengths of ultraviolet light B (UVB) represent a biologically very active part of it (2). The chromophores transduct the electromagnetic energy of UVB into neural, chemical and hormonal signals to produce rapid (neural) or slow (humoral or immune) responses at the local and systemic levels $(3,4)$. Skin irradiated by UVB can activate both the central and local hypothalamic-pituitary-adrenal (HPA) axis to turn on homeostatic responses and deactivate local and systemic damage $(5,4)$. Locally UVB irradiation of the skin leads to activation of pro-opiomelanocortin (POMC) and corticotropin releasing hormone $(\mathrm{CRH})$ in epidermal and dermal skin, produces cutaneous POMC peptides and activates the corresponding receptors that are important regulators on the pigmentary and the inflammatory reactions. $(6,7,8)$ In addition keratinocytes stimulated by UVB can, as a rapid effect, secrete e.g., interleukin-1 $\beta$ (IL-1 $\beta$ ), IL-6 and tumor necrosis factor (TNF) (26). The transmission of UV radiation to the skin depends decisively on the individual skin type and UV adaptation status. UV wavelegths below $305 \mathrm{~nm}$ are almost totally absorbed into the stratum corneum and epidermis. For UV wavelengths above $305 \mathrm{~nm}$ about $10 \%$ reach the dermis. No UV radiation penetrates through the dermis to the subcutaneous adipose tissue. $(1,9,10)$.

The skin epithelium is one of the most actively proliferating tissues in the human body and characterized by an approximately 24 -hour rhythm in almost all its functions $(11,12)$ These circadian rhythms are regulated by an endogenous time-keeping system, the circadian clock. The central pacemaker of human circadian rhythms is located in the suprachiasmatic nucleus (SCN) of the anterior hypothalamus in the brain, while peripheral tissues follow the pace at transcriptional levels using a transcriptional-translational feedback loop (13). The 
genes involved in the regulation and maintenance of the circadian rhythms are called clock genes. Canonical clock genes, such as cryptochrome circadian clocks (CRY1, CRY2), encode proteins which interact with each other to build up an autoregulatory feedback loop $(14,15)$. The CRY1/CRY2 ratio alters the circadian period, an increasing ratio being associated with a longer circadian period (16). CRY1 or CRY2 as well as the period circadian clock (PER1 or PER2) as dimers are transcriptional repressors in the core transcription-translation feedback loop (17). Aryl hydrocarbon receptor nuclear translocator-like (ARNTL) protein is the key circadian clock protein and a transcription factor of $C R Y 1$ and $C R Y 2$ genes (18).

There is a daily rhythm in the expression of circadian associated repressor of transcription $(C I A R T)$ gene, and it is also regulated by stress responses (19). CIART protein has been shown to have a role in the transcriptional regulation of clock-controlled genes, as it can repress circadian locomotor output cycles kaput (CLOCK) and ARNTL protein activity in different time-windows from CRY proteins and PER proteins $(20,15)$. In a diurnal primate, the baboon, the most frequent cycling gene was Ciart, as it was cycling in 52 of the 64 tissues sampled every two hours over a period of 24 hours, and the expressions of the seven main clock genes in the diurnal baboon and in the nocturnal mouse were in antiphase to each other (21). Circadian clock proteins and genes have been shown to regulate cellular responses after UVB exposure: in mice, sensitivity to UVB-induced DNA damage in the epidermal skin is a process that is dependent on ARNTL as a function of the time of day $(22,23)$. Earlier we showed the effect on circadian timing in UVB-induced erythema response in human epidermal/dermal skin (24). However, the effect of UVB radiation on clock genes is not fully understood.

This article is protected by copyright. All rights reserved. 
Human skin cells are known to express circadian clock proteins (25), but very little is so far known about the regulation of their expression and activity. In adipose tissue CIART gene oscillates with a circadian frequency (26). In addition, human adipocytes express other clock genes $(27,28)$, but as far as we know there is no earlier data on whether the clock genes are expressed in the subcutaneous adipose tissue after UVB exposure. The effects of UVR on subcutaneous adipose tissue are transmitted through cytokines such as IL-6, IL-8, monocyte chemoattractant protein-3 (MCP-3) and placenta growth factor (PlGF) (29) and signal transduction can occur through melanocortin receptors (MC1R and MC2R) (30).

Our aim was to explore the effects of UVB on mRNA levels of $C R Y 1, C R Y 2$, and CIART genes in the skin of healthy volunteers. We also investigated for the first time whether the effects of UVB on circadian gene expression extend from epidermal/dermal skin to the subcutaneous adipose tissue and measured amounts of mRNA of the $I L-1 \beta, I L-6, T N F$, $P O M C$, and melanocortin receptors $(M C R 1 / M C R 2)$ in the both tissues to confirm earlier findings and find possible link between UVB and clock proteins below the skin surface.

\section{MATERIALS AND METHODS}

Healthy adult volunteers $(n=12)$ presenting with anamnestic skin phototypes II or III (31) were eligible to participate. The skin phototype was confirmed in a clinical interview. Subjects with photosensitizing, immune modulating or psychiatric medication, photosensitivity, pregnancy, lactation, history of skin cancer or extensive scarring, or marked UVR exposure in the three preceding months were not eligible to participate. During the study no medication was allowed. Three subjects had recently taken some medication and to meet the inclusion criteria this had to be discontinued for a minimum of 48 hours before the beginning of the study.

This article is protected by copyright. All rights reserved. 


\section{Ethics}

This study was carried out in the Department of Dermatology, Päijät-Häme Central Hospital, Lahti, Finland, from January to April 2016. Written informed consent was obtained from the participants and the ethics committee of Hospital District of Pirkanmaa approved the study protocol (\#R16001)

\section{UVB radiation}

One square $\mathrm{cm}$ area of the buttock skin was exposed to 4 standard erythemal dose (SED), while the rest of the skin was protected. A Waldmann UV 801KL phototherapy device equipped with 4 TL20W/01 narrowband UVB (NB-UVB) tubes was used for UVB irradiations. The bulbs were preheated for seven minutes before the exposure. The irradiance of the device was measured before the study using an Ocean Optics S2000 spectroradiometer by the Nuclear Safety Authority of Finland. The time to irradiate the test area was calculated on the basis of these measurements so that the 4 SED area was irradiated for $6 \min 28 \mathrm{sec}$. One SED is defined as an erythemal effective radiant exposure of $10 \mathrm{~mJ} / \mathrm{cm}^{2}$, and is equivalent to a non-weighted physical UV dose of $172 \mathrm{~mJ} / \mathrm{cm}^{2}$ emitted from our narrowband UVB lamps. The 4 SED thus equals a non-weighted physical dose of $688 \mathrm{~mJ} / \mathrm{cm}^{2}$. Most of the radiation of the narrowband UVB lamp's radiation is in the $311 \mathrm{~nm}$ emission peak. The spectrum of the narrowband UVB lamps is presented in Figure 1. Uncertainty $(2 \sigma)$ of the measurement of the OceanOptics S2000 was estimated to be approximately $14 \%$ (32). The measurements are traceable to the National Institute of Standards and Technology (Gaithersburg, Maryland, USA). 


\section{Sample collection}

While the narrowband UVB irradiation was administered in the morning between 7 a.m. and 9 a.m. on day one, the $3 \mathrm{~mm}$ skin punch biopsies, consisting of epidermis/dermis and subcutaneous adipose tissue, were sampled 24 hours after the exposure on day two. A nonirradiated skin control biopsy was obtained at least $10 \mathrm{~cm}$ away from the irradiated skin square, and had been protected against UVB with impermeable fabric. Lidocaine $1 \%$ without epinephrine was used for local anesthesia, and the punch biopsies were obtained thereafter. The subcutaneous adipose tissue and epidermis/dermis were cut separately from each other with a scalpel and incubated separately. All samples were incubated in RNAlater (Thermo Fischer Scientific, Massachusetts, USA) for 24 hours at $+4^{\circ} \mathrm{C}$, and thereafter deep-frozen and stored at from $-80^{\circ} \mathrm{C}$ to $-20^{\circ} \mathrm{C}$ until mRNA extraction.

\section{Total-RNA extraction, cDNA synthesis and RT-PCR}

Both epidermis/dermis and subcutaneous adipose tissue samples were mechanically homogenized by Ultra-turrax homogenizer (IKA-Analysentechnik) in RLT buffer (Qiagen, Hilden, Germany). To sediment the small tissue pieces and to layer possible fat, the homogenates were centrifuged twice at $12000 \times \mathrm{g}$ for $10 \mathrm{~min}$ at $+4^{\circ} \mathrm{C}$. Total RNA from epidermal/dermal skin biopsies was isolated using AllPrep kit (Qiagen, Venlo, The Netherlands). Four hundred micrograms of RNA was reverse transcribed with High Capacity cDNA Reverse Transcription kit (Applied Biosystems, Foster City, CA, U.S.A.) to cDNA as previously described (33). And from subcutaneous adipose tissue, $80 \square \mathrm{g}$ of RNA was reverse-transcribed with VILO kit (Thermo Fisher Scientific/Invitrogen, Carlsbad, CA, U.S.A.) according to manufacturer's instructions. The expression of the 
cytokines and genes involved in the circadian rhythm were studied by TaqMan 7500 Fast System (Applied Biosystems) with PerfeCTa qPCR FastMix (Quanta Biosciences, Gaithersburg, MD, U.S.A.). PCR primers and probes for cytokines and chemokines were obtained as predeveloped assay reagents from Applied Biosystems. Ribosomal 18S gene was used as housekeeping gene in the TaqMan analyses.

\section{Statistics}

Gene expressions of selected circadian genes and cytokines were first compared using ordinary one-way ANOVA at different time points. Statistical analysis of target gene expression was performed with the nonparametric Mann-Whitney test before and after UVB treatment. A single apparent outlier from the null samples was excluded from the analysis. The association between the expression of $C R Y 1$ and $C R Y 2$ in the skin at different time points was examined using the Pearson's correlation test. All statistical analyses were performed with GraphPad Prism 7 Software (GraphPad Software Inc., San Diego, California).

\section{RESULTS}

Altogether 12 healthy subjects participated in the study, 2 men and 10 women, aged 41 (26 to 64) years on average and with BMI 23.5 (SD \pm 3.4$)$ on average. Four presented with anamnestic skin phototype II and eight with phototype III (31). We found the epidermal/dermal skin mRNA of $C R Y 2$ gene to be at a lower level of expression after UVB irradiation than skin without irradiation. We also found that in the null epidermal/dermal skin sample there was 6.5 times more and in the subcutaneous adipose tissue as much as 20 times more $C R Y 2$ than $C R Y 1$ mRNA.

This article is protected by copyright. All rights reserved. 


\section{Clock gene expressions after UVB}

After the UVB exposure expression of $C R Y 2$ mRNA in epidermal/dermal skin was significantly decreased $(\mathrm{p}=0.0492)$, and a similar tendency was seen in CIART mRNA (Figure 2a). UVB irradiation of the skin had no statistically significant impact on the expression of epidermal/dermal skin $C R Y 1 \mathrm{mRNA}$, but changes in gene expression were seen in the subcutaneous adipose tissue; UVR significantly enhanced the expression of CRY1 ( $\mathrm{p}=0.0263)$ (Figure 2b). The expression of CIART also enhanced $(\mathrm{p}=0.0411)$ and a small increase was seen in $C R Y 2$. We found a positive linear correlation between $C R Y 2$ and CRY1 mRNA amounts in epidermal/dermal skin, especially after irradiation ( $\mathrm{r}=0.84)$ (Figure 3a) and the $C R Y 1 / C R Y 2$ ratio was significantly different after irradiation $(\mathrm{p}=0.0011)$. In subcutaneous adipose tissue the correlation was weak (Figure 3b).

\section{UVB modifies cytokine expressions in skin but not in adipose tissue}

UVB exposure significantly enhanced the expression of interleukin- $1 \beta(I L-1 \beta)$ mRNA in the epidermal/dermal skin $(\mathrm{p}=0.0011)$, and a similar tendency was also observed in the expression of $T N F$ (Figure 4a). UVB exposure did not induce clear changes in $I L-6$ after 24 hours. No significant changes in the subcutaneous adipose tissue were seen in the cytokine expressions studied (Figure 4b). A small increase was also seen after UVB exposure in $P O M C$ and melanocortin 1 receptor $(M C 1 R)$, both in the epidermal/dermal skin and subcutaneous adipose tissue. melanocortin 2 receptor $(M C 2 R)$ level showed no significant change (Figure 4a-b).

This article is protected by copyright. All rights reserved. 


\section{DISCUSSION}

In addition to epidermal/dermal skin UVB radiation seems also to affect mRNA expression in the subcutaneous adipose tissue. We found $C R Y 2$ expression to be down-regulated in epidermal/dermal skin following UVB radiation, and in subcutaneous adipose tissue $C R Y 1$ and CIART expression appeared to be up-regulated. The differences in trend in the two tissues with CRY2 and CIART genes may be due to the fact that no NB-UVB penetrates into the subcutaneous adipose tissue.

In humans and other mammals visible light is capable of interacting with the master circadian clock through retinal rods, cones, and ganglion cells that project information from the eyes to the SCN (34-38). Both CRY1 and CRY2 have been detected in the human retina by immunohistochemistry (39) and can function as blue-light photoreceptors, but may even be more sensitive to shorter (from $300 \mathrm{~nm}$ to $450 \mathrm{~nm}$ ) UV- wavelengths $(40,41)$. While the SCN is a pacemaker and the main link between the circadian clock and light exposure, in plants and animals peripheral clocks play a role in perceiving changes in environmental radiation (42), which, based on CRY1 and CRY2 signaling mechanisms, may also be possible in humans (43). In the human retina CRY2 mRNA is 11 times more abundant than CRY1 and expected to capture the photons necessary to initiate a light-sensitive response (39). We found that in untreated control skin there was 6.5 times and in the subcutaneous adipose tissue as much as 20 times more $C R Y 2$ than $C R Y 1$ mRNA, which corroborates the putative role of CRY2 protein interactions with UVB. Although UVB induced mRNA expressions of the clock genes have not been studied earlier in vivo, in cultured human keratinocytes UVB downregulated ARNTL, CLOCK and PERl gene expressions. (44).

This article is protected by copyright. All rights reserved. 
The observed change in clock genes due to UVB may affect the repair of UVR- induced damage. In mice inflammatory cytokine induction, sunburn apoptosis, and erythema are controlled by circadian rhythm (22). Huber et al. suggested that CRY2 can limit tumor formation by promoting the turnover of c-MYC, a critical regulator of cell proliferation (45). This observation is in line with our earlier finding that human skin with a neglible amount of CRY2 showed more erythema (24). While we now found CRY2 expression to be downregulated in epidermal/dermal skin following UVB radiation, is possible that UVB exposure undermines the protective mechanisms in epidermal/dermal skin.

Since after UV exposure proinflammatory cytokines IL-1, IL-6, and TNF are expressed in various skin cell types (30), we expected to detect a significant increase in their mRNA levels. Based on cytokine mRNA levels a slight inflammation occurred in the epidermal/dermal skin but not in the subcutaneous adipose tissue. As UVB induces POMC, we expected to see a significant increase in the expression of POMC mRNA when comparing the irradiated and non-irradiated skin specimens. The UVB dose used in our study was large enough to induce visible erythema at $24 \mathrm{~h}$, whereas the increase in pigmentation takes more time (46). It is thus possible that later timing of biopsy, e.g. some days later, would have revealed a more pronounced increase in POMC mRNA. However, we already detected a small increase in POMC mRNA expression both in the epidermal/dermal skin and subcutaneous adipose tissue at $24 \mathrm{~h}$ after exposure, which may indicate that later sampling might have worked better for detecting POMC mRNA. As we found no proof of the involvement of melanocortin receptors in signaling between UVB and chryptocromes in adipose tissue at $24 \mathrm{~h}$, these could be expressed later at 3 to 6 days, when pigmentation reaches its maximum (46).

This article is protected by copyright. All rights reserved. 
As we detected an increase in the $C R Y 1 / C R Y 2$ ratio after irradiation, it is possible, in light of earlier findings, that UVB extends the circadian period (16). In addition melatonin produced in epidermal/dermal skin may play a role in the UVB damage responses and mRNA synthesis of clock proteins, but this needs to be clarified in future clinical studies (47). Due to the important role that circadian functions play in the human body, it is essential to understand the mechanisms behind the circadian clock of the metabolic active tissue, the subcutaneous adipose tissue, as part of the skin. As clock genes in adipose tissue have been linked to the metabolic syndrome (48) our data opens up a new perspective when considering the implications of UVR exposure for human health. Unfortunately a limitation of our study is the relatively small number of participants and the fact that we only measured mRNA but not proteins, which is due to the invasive nature. Larger cohorts are needed to confirm these links from UVB to adipose tissue disturbances.

\section{CONCLUSION}

We investigated the effect of UVB radiation on the expression of key clock genes in epidermal/dermal skin and subcutaneous adipose tissue, showing for the first time that UVB radiation affects expression of circadian genes in the subcutaneous adipose tissue. Variation in the expression of CIART gene suggests that it is a possible oscillator of skin functions. More studies are warranted to understand further actions and mechanisms of clock genes in detail. Our findings suggest that UVB may influence peripheral clock genes in the skin to modulate e.g. cellular responses against to UVR induced damage.

This article is protected by copyright. All rights reserved. 


\section{CONFLICT OF INTEREST}

The authors report no conflict of interest.

\section{ACKNOWLEDGEMENTS}

This study was financially supported by the Competitive State Research Financing of the Expert Responsibility area of Tampere University Hospital. We gratefully acknowledge our research nurse Ulla Oesch-Lääveri for her dedication in the implementation of the study, and MSc Terhi Vesa for her excellent technical assistance in the nucleic acid purifications and quantitative analyses. The first author V.N. and M.G. took part in the planning of the study protocol, implemented all UVB irradiations and samplings, authors P.K., M.M. and H.A. performed the mRNA analyses, statistical tests, and produced the figures, L.Y was responsible for UVR dosimetry, all authors took part in the evaluation of results and writing. T.P. and E.S. jointly steered the whole study.

\section{REFERENCES}

1. D'Orazio J, Jarrett S, Amaro-Ortiz A, Scott T. UV radiation and the skin. Int J Mol Sci $2013 ; 14: 12222-48$.

2. Freeman SE, Hacham H, Gange RW, Maytum DJ, Sutherland JC, Sutherland BM. Wavelength dependence of pyrimidine dimer formation in DNA of human skin irradiated in situ with ultraviolet light. Proc Natl Acad Sci USA 1989;86:5605-9.

3. Slominski AT, Zmijewski MA, Skobowiat C, Zbytek B, Slominski RM, Steketee JD. 
Sensing the environment: Regulation of local and global homeostasis by the skin neuroendocrine system. Adv Anat, Embryol Cell Biol 212: 1-115, 2012.

4. Slominski AT, Zmijewski MA, Plonka PM, Szaflarski JP, Paus R.How UV Light Touches the Brain and Endocrine System Through Skin, and Why. Endocrinology 159(5), 1992-2007, 2018.

5. Slominski AT, Zmijewski MA, Zbytek B, Tobin DJ, Theoharides TC, Rivier J. Key Role of CRF in the Skin Stress Response System. Endocrine Rev 34:827-84, 2013.

6. Slominski A, Wortsman J, Luger T, Paus R, Solomon S. Corticotropin Releasing Hormone and Proopiomelanocortin Involvement in the Cutaneous Response to Stress. Physiol Rev 80, 979-1020, 2000.

7. Slominski A, Tobin DJ, Shibahara S, Wortsman J. Melanin Pigmentation in Mammalian Skin and Its Hormonal Regulation. Physiol Rev 84, 1155-1228, 2004.

8. Slominski A, Tobin DJ, Paus R. Does p53 regulate skin pigmentation by controlling proopiomelanocortin gene transcription? Pigment Cell Res 20, 307-308, 2007.

9. Dakup P, Gaddameedhi S. Impact of the circadian clock on UV-Induced DNA damage response and photocarcinogenesis. Photochem Photobiol 2017;93:296-303.

10. Matsui MS, Pelle E, Dong K, Pernodet N. Biological rhythms in the skin. Int J Mol Sci $2016 ; 24 ; 17$

11. Bruls WA, Slaper, H, van der Leun JC, Berrens L. Transmission of human epidermis and stratum corneum as a function of thikness in the ultraviolet and visible wavelengths. Photochem Photobiol. 1984;40: 485-494.

12. Meinhardt M, Krebs R, Anders A, Heinrich U, Tronnier H. Absorption spectra oh human skin in vivo in the ultraviolet wavelength ranga measured by optoacoustics. Photochem and Photobiol. 2009;85;70-77.

This article is protected by copyright. All rights reserved. 
13. Panda S, Hogenesch JB, Kay SA. Circadian rhythms from flies to human. Nature 2002;417:329-35.

14. King DP, Takahashi JS. Molecular genetics of circadian rythms in mammals. Annu Rev Neurosci. 2000;23:713-42.

15. Goriki A, Hatanaka F, Myung J, Kim JK, Yoritaka T, Tanoue S, et al. A novel protein, CHRONO, functions as a core component of the mammalian circadian clock. PLOS Biol 2014;12:1-15.

16. Papp SJ, Huber A-L, Jordan SD, Kriebs A, Nguyen M, Moresco JJ, et al. DNA damage shifts circadian clock time via Hausp-dependent Cry1 stabilization. eLife 2015;4: e04883.

17. Reppert SM, Weaver DR. Coordination of circadian timing in mammals. Nature 2002;418:935-41.

18. Lowrey PL, Takahashi JS. Genetics of Circadian Rhythms in Mammalian Model Organisms. Adv Genet. 2011;75:173-230.

19. Hatanaka F, Takumi T. CHRONO integrates behavioral stress and epigenetic control of metabolism. Ann Med 2017;49:352-6.

20. Annayev Y, Adar S, Chiou Y, Lieb JD, Sancar A, Ye R. Gene model 129 ( Gm129 ) encodes a novel transcriptional repressor that modulates circadian gene expression. $\mathbf{J}$ Biol Chem 2014;289:5013-24.

21. Mure LS, Le HD, Benegiamo G, et al. Diurnal transcriptome atlas of a primate across major neural and peripheral tissues. Science. 2018;359:6381

22. Gaddameedhi S, Selby CP, Kemp MG, Ye R, Sancar A. The circadian clock controls sunburn apoptosis and erythema in mouse skin. J Invest Dermatol 2015;135:1119-27. 
23. Geyfman M, Kumar V, Liu Q, et al. Brain and muscle Arnt-like protein-1 (BMAL1) controls circadian cell proliferation and susceptibility to UVB-induced DNA damage in the epidermis. Proc Natl Acad Sci U S A 2012;109:11758-63.

24. Nikkola V, Grönroos M, Huotari-Orava R, Kautiainen H, Ylianttila L, Karppinen T, et al. Circadian time effects on NB-UVB-induced erythema in human skin in vivo. $\mathrm{J}$ Invest Dermatol 2018;138:464-7.

25. Zanello SB, Jackson DM, Holick MF. Expression of the circadian clock genes clock and period1 in human skin. J Invest Dermatol 2000;115:757-60.

26. Anafi RC, Lee Y, Sato TK, Venkataraman A, et al. Machine learning helps identify CHRONO as a circadian clock component. PLoS Biol 2014;12.

27. Otway DT, Mäntele S, Bretschneider S, Wright J, Trayhurn P, Skene DJ, et al. Rhythmic diurnal gene expression in human adipose tissue from individuals who are lean, overweight, and type 2 diabetic. Diabetes 2011;60:1577-81.

28. Vieira E, Ruano Eg, Figueroa AL, Aranda G, Momblan D, Carmona F, et al. Altered clock gene expression in obese visceral adipose tissue is associated with metabolic syndrome. PLoS One 2014;9:e111678.

29. Kim EJ, Kim YK, Kim JE, Kim S, Kim M-K, Park C, et al. UV modulation of subcutaneous fat metabolism. J Invest Dermatol 2011;131:1720-6.

30. Slominski A, Wortsman J. Neuroendocrinology of the skin. Endocr Rev 2000;21:45787.

31. Fitzpatrick TB. The validity and practicality of sun-reactive skin types I through VI. Arch Dermatol 1988:124:869-871.

32. Ylianttila L, Visuri R, Huurto L, Jokela K. Evaluation of a single-monochromator diode array spectroradiometer for sunbed UV-radiation measurements. Photochem

This article is protected by copyright. All rights reserved. 
Photobiol 2005;81:333-341.

33. Wang G, Savinko T, Wolff H, Dieu-Nosjean MC, Kemeny L, Homey B, et al. Repeated epicutaneous exposures to ovalbumin progressively induce atopic dermatitislike skin lesions in mice. Clin Exp Allergy 2007;37:151-61.

34. Berson DM. Phototransduction in ganglion-cell photoreceptors. Pflugers Arch. 2007:849-55.

35. Guler AD, Altimus CM, Ecker JL, Hattar S. Multiple photoreceptors contribute to nonimage-forming visual functions predominantly through melanopsin-containing retinal ganglion. Cold Spring Harb Symp Quant Biol 2007;72:509-15.

36. Hannibal J, Hindersson P, Knudsen SM, Georg B, Fahrenkrug J. The photopigment melanopsin is exclusively present in pituitary adenylate cyclase-activating polypeptide-containing retinal ganglion cells of the retinohypothalamic tract. $\mathrm{J}$ Neurosci 2002;22:1-7.

37. Hattar S, Liao H-W, Takao M, Berson DM, Yau K-W. Melanopsin-containing retinal ganglion cells: architecture, projections, and intrinsic photosensitivity. Science 2001;295:1065-70.

38. Hannibal J, Hindersson P, Østergaard J, Georg B, Heegaard S, Larsen PJ, et al. Melanopsin is expressed in PACAP-containing retinal ganglion cells of the human retinohypothalamic tract. Investig Ophthalmol Vis Sci 2004;45:4202-9.

39. Thompson CL, Rickman CB, Shaw SJ, Ebright JN, Kelly U, Sancar A, et al. Expression of the blue-light receptor cryptochrome in the human retina. Invest Ophthalmol Vis Sci. 2003 44:4515-21.

40. Foley LE, Gegear RJ, Reppert SM. Human cryptochrome exhibits light-dependent magnetosensitivity. Nat Commun. 2011: 2:356

This article is protected by copyright. All rights reserved. 
41. Hsu DS, Zhao X, Zhao S, Kazantsev A, Wang R-P, Todo T. Putative human blue-light photoreceptors hCRY1 and hCRY2 are flavoproteins. Biochemistry 1996;35:13871-7.

42. Chaves I, Pokorny R, Byrdin M, Hoang N, Ritz T, Brettel K, et al. The cryptochromes: blue light photoreceptors in plants and animals. Annu Rev Plant Biol. 2011;62:335-64.

43. Vieira J, Jones AR, Danon A, Sakuma M, Hoang N, Robles D, et al. Human cryptochrome-1 confers light independent biological activity in transgenic drosophila correlated with flavin radical stability. PLoS One 2012;7: e31867.

44. Kawara S, Mydlarski R, Mamelak AJ, Freed I, Wang B, Watanabe H, et al. Low-dose ultraviolet B rays alter the mRNA expression of the circadian clock genes in cultured human keratinocytes. J Invest Dermatol 2002;119:1220-3.

45. Huber AL, Papp SJ, Chan AB, Henriksson E, Jordan SD, Kriebs A, et al. CRY2 and FBXL3 cooperatively degrade c-MYC. Mol Cell 2016.

46. Suh KS, Roh H J, Choi SY, Jeon YS., Doh KS, Bae JH, et al. A long-term evaluation of erythema and pigmentation induced by ultraviolet radiations of different wavelengths. Ski Res Technol 2007;13:360-8.

47. Slominski AT, Hardeland R, Zmijewski MA, Slominski RM, Reiter RJ, Paus R. Melatonin: A Cutaneous Perspective on its Production, Metabolism, and Functions J Invest Dermatol 138:490-499, 2018.

48. Gómez-Abellán P, Hernández-Morante JJ, Luján JA, Madrid JA, Garaulet M. Clock genes are implicated in the human metabolic syndrome. Int J Obes 2008;32:121-8.

This article is protected by copyright. All rights reserved. 


\section{LEGENDS FOR ILLUSTRATION}

Figure 1. The spectrum of the narrowband UVB lamp TL01. The spectrum has an emission maximum at $311 \mathrm{~nm} .63 \%$ of the lamps $\mathrm{UV}$ and visible $(280-780 \mathrm{~nm})$ radiation is in the narrow $305-315 \mathrm{~nm}$ band. The UVB $(280-315 \mathrm{~nm})$ range contains $64 \%$, UVA (315 $400 \mathrm{~nm}) 16 \%$ and visible light (400 $-780 \mathrm{~nm}) 19 \%$ of the lamps UV and visible light radiation.

Figure 2. Circadian gene expression in a) epidermal/derman skin and in b) subcutaneous adipose tissue $24 \mathrm{~h}$ after four SED UVB exposure. The total number of samples in group is 11-12. Nonparametric Mann-Whitney test was used to represent the column of group means, and standard errors of the means (SEM). Ctrl, untreated control skin; UV, UVtreated skin; RU, relative units. ${ }^{*} \mathrm{p}<0.05$

Figure 3. Correlation between $C R Y 1$ (y-axis) and CRY2 (x-axis) in UV-exposed and control tissues in a) epidermal/dermal skin and in b) subcutaneous adipose tissue $24 \mathrm{~h}$ after four SED UVR exposure. The total number of samples in a group is 11. Linear regression was used to model the data per CRY2, and Pearson's correlation was used to compute the correlation coefficients (r). Ctrl, untreated control skin; UV, UV-treated skin. $* * \mathrm{p}<0.005$

Figure 4. Cytokine, POMC and melanocortin receptor gene expression in a) skin and in b) subcutaneous adipose tissue $24 \mathrm{~h}$ after four SED UVR exposure. The total number of samples in group is 11-12. Nonparametric Mann-Whitney test was used to represent the group means and standard errors of the means (SEM). Ctrl, untreated control skin; UV, UVtreated skin. $* \mathrm{p}<0.05, * * \mathrm{p}<0.005$ 
Figure 1

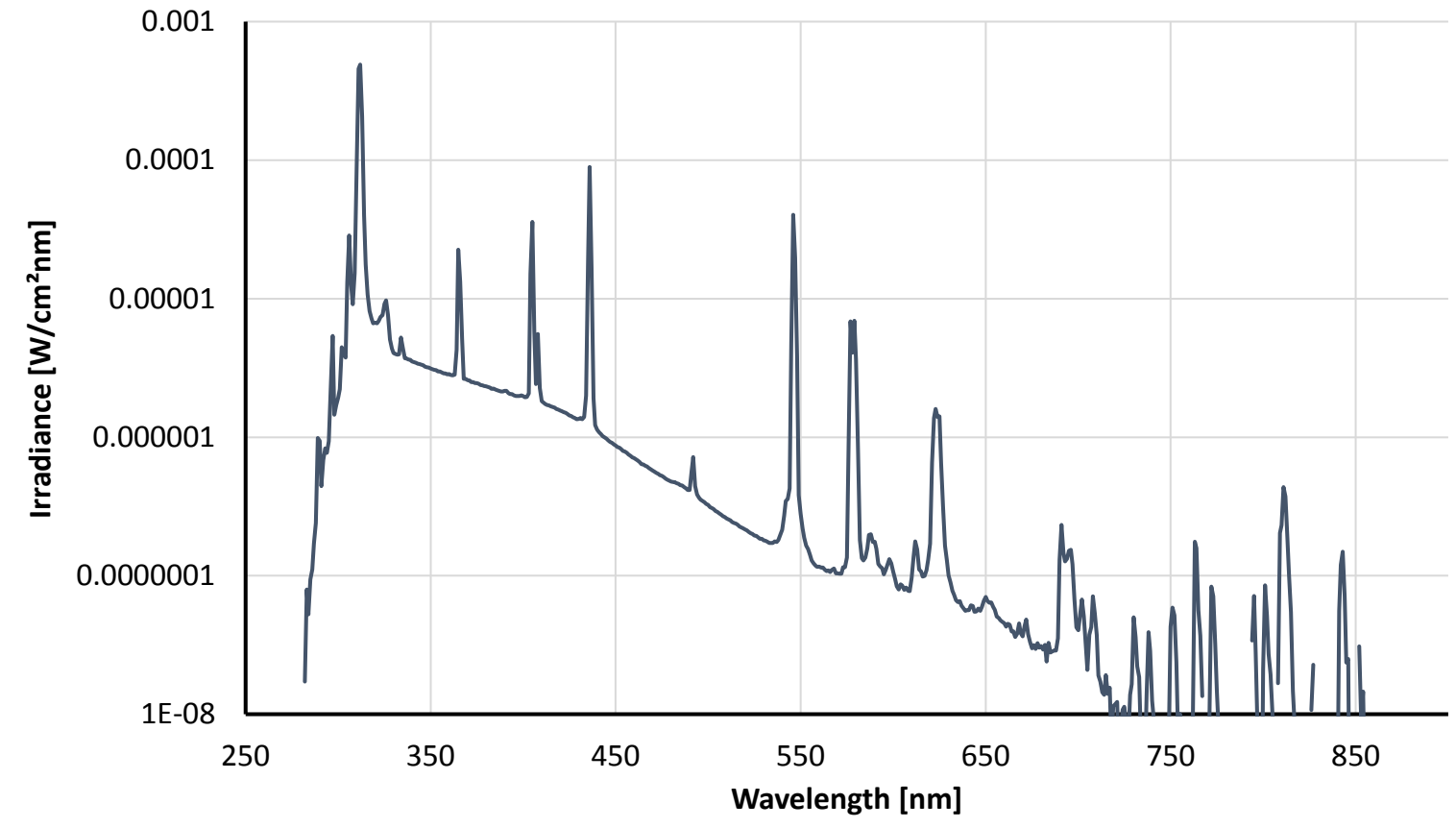

Figure 2.

a



b

This article is protected by copyright. All rights reserved. 


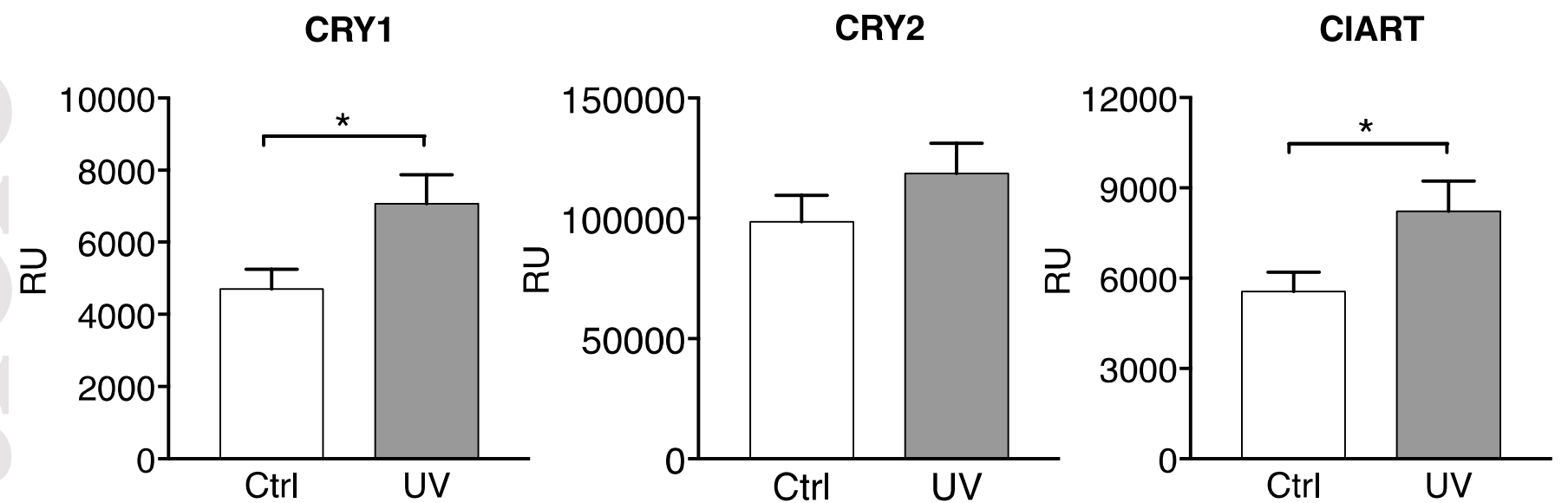

Figure 3

b

Epidermal skin

Subcutaneous fat

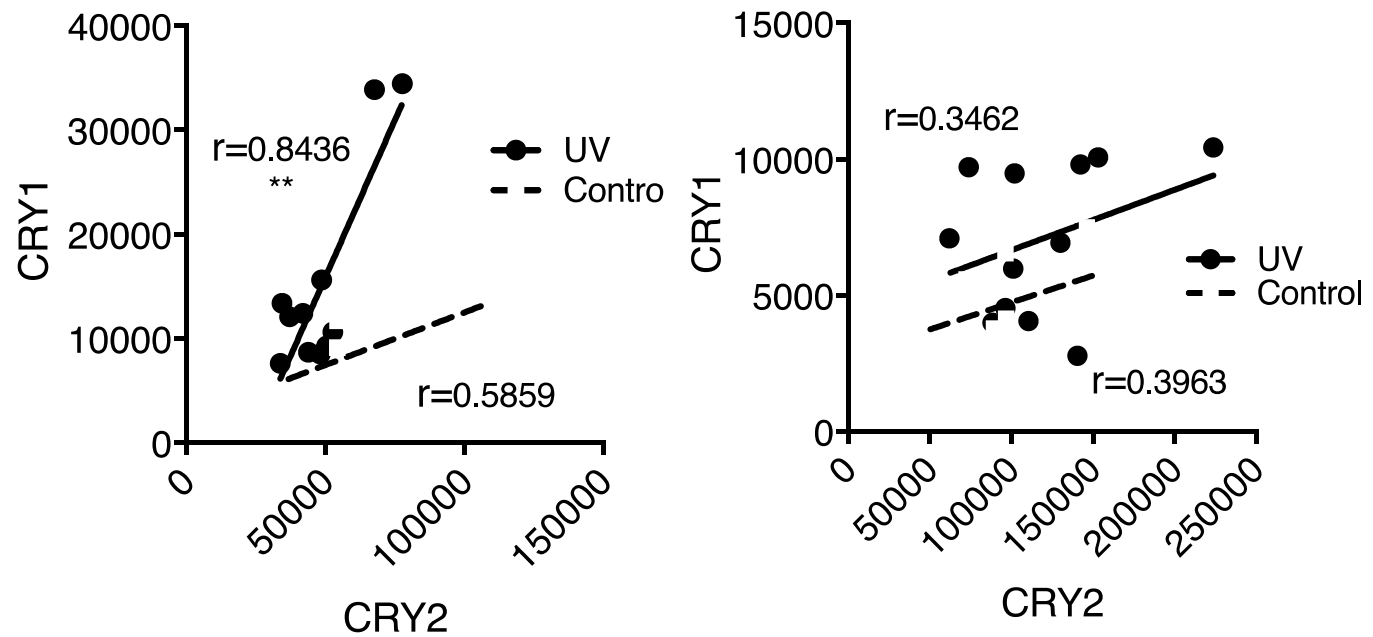

This article is protected by copyright. All rights reserved. 


\section{Figure 4}



This article is protected by copyright. All rights reserved. 